\title{
SHARING ECONOMY - CHALLENGES AND REGULATORY REQUIREMENTS
}

\section{PIOTR ŁADNY}

University of Szczecin, Faculty of Management and Economics of Services, POLAND

e-mail: piotr.ladny@serviceinterlab.pl

\begin{tabular}{l|l}
$\begin{array}{l}\text { RECEIVED } \\
\text { ACCEPTED }\end{array}$ & $\begin{array}{l}6 \text { November } 2018 \\
\text { J December } 2018\end{array}$ \\
CLASSIFICATION & L51,014 \\
KEYWORDS & sharing economy, collaborative economy, regulation \\
ABSTRACT & $\begin{array}{l}\text { The article presents the sharing/collaborative economy and the pillars on which the development of this phe- } \\
\text { nomenon is based. On the example of Uber and Airbnb, the most important social and economic effects of this } \\
\text { phenomenon are characterized. The reasons for taking regulatory actions in this sector were also indicated. } \\
\text { Based on international experience, the principles of creating a legal framework for sharing economy were } \\
\text { indicated. }\end{array}$
\end{tabular}

\section{Introduction}

Information technologies are one of the main factors changing the world around us to the extent that is often referred to as a revolution. One of the manifestations of changes taking place is the emergence in the economic and social space of a phenomenon related to the joint use of human and material resources and the growing acceptance of the possibility of using resources instead of having them. The phenomenon, known as sharing economy (SE), is 
based on the mutual provision of services by people and the joint use of resources such as tangible goods, financial resources, skills or time.

The idea of sharing things and using them together is not new and has been known by humanity from the beginning. However, in the past, the extent to which resources and skills were made available and shared was rather limited, mainly due to the technical difficulties associated with matching and communication of people who have the resources and people who would like to use these resources. Another problem was the lack of trust between strangers, which meant that the joint use of goods was only between people who were members of small communities or families.

It was the creation of online platforms enabling an easy search for available resources by those who would like to use them, and the introduction of reputation assessment systems (customer reviews) that reduced search costs, eliminated the lack of trust, and through the use of economies of scale led to the emergence and rapid development of sharing economy.

Data on the USA show that in 2016, 44.8 million of U.S. adults used the sharing economy, and it's expected to grow to 86.5 million U.S. users by 2021. A Time magazine poll published in January 2016 estimated that $42 \%$ of Americans had already used a sharing economy service, and that $22 \%$ had provided one (Cusumano, 2018, pp. 26-28). It is estimated that the number of people using cooperation platforms will double by 2021.

In EU countries, the popularity of SE is smaller. According to a survey conducted in April 2018 by the European Commission, $23 \%$ respondents (17\% in 2016) used the platforms offering SE services, and $6 \%$ offered their goods or services in this way. Of all respondents, the largest group (14\%) have used services in the accommodation sector, while $12 \%$ have done so in the transport sector (European Commission, 2018, pp. 7-8, 11).

\section{Sharing economy - characteristics and effects}

Although the term economy sharing has existed in theory and practice for several years, it is difficult to find in literature a common, more commonly accepted definition of this concept. Analysis of the literature on the subject allows for indicating several dozen different definitions, some of which address this issue narrowly, reducing it in its essence to, for example, the operation of online platforms or mobile applications (Laurell, Sandström, 2017, pp. 58-65; Muñoz, Cohen, 2017, pp. 21-37), the functioning and role of intermediaries between the exchange participants (Mair, Reischauer, 2017, pp. 11-20) or business models based on fees charged for access to the functions of products, not their possession, while excluding non-commercial activities from this area (Zervas, Proserpio, Byers, 2017, pp. 687-705).

Another approach treats the SE broadly, as a phenomenon that refers to almost every manifestation of social and economic life. It concerns various areas, sectors of the economy, business models and lifestyles or management styles and is based on various elements (Owyang, 2016). The SE term itself is also used interchangeably with such terms as: collaborative economy, collaborative consumption, access-based consumption, connected consumption. The sharing economy is an element of collaborative consumption which is an economic model based on the access to property and sharing of resources (Budziewicz-Guźlecka, 2017, pp. 27-36).

In 2016, due to the difficulties to apply the definition of "sharing or collaborative economy" to companies as Uber, Airbnb, the US Department of Commerce's Economics and Statistics Administration has proposed a new definition of "digital matching firms" that exhibit the following characteristics (DC, 2016): 
1. They use information technology, typically available via webbased platforms, such as mobile apps on Internet- enabled devices, to facilitate peer-to-peer transactions.

2. They rely on user-based rating systems for quality control, ensuring a level of trust between consumers and service providers who have not previously met.

3. They offer the workers who provide services via digital matching platforms flexibility in deciding their typical working hours.

4. To the extent that tools and assets are necessary to provide a service, digital matching firms rely on the workers using their own.

An attempt to clarify the concept and indicate the type of activity to which it refers was made by the European Commission, which in June 2016 published the document A European agenda for the collaborative economy, which adopted a very broad understanding of collaborative economy/sharing economy (these concepts are treated as synonyms).

The term "collaborative economy" refers to business models where activities are facilitated by collaborative platforms that create an open marketplace for the temporary usage of goods or services often provided by private individuals. The collaborative economy involves three categories of actors:

- service providers who share assets, resources, time and/or skills - these can be private individuals offering services on an occasional basis ("peers") or service providers acting in their professional capacity ("professional services providers"),

- users of these,

- intermediaries that connect - via an online platform - providers with users and that facilitate transactions between them ("collaborative platforms"). Collaborative economy transactions generally do not involve a change of ownership and can be carried out for profit or not-for-profit (European Commission, 2016).

Regardless of the discussion about the concept of SE and the context in which it is used, among scientists and practitioners dealing with this area, the discussion on the social and economic effects of SE development intensifies. The EU documents emphasize that sharing/collaborative economy creates new opportunities for consumers and entrepreneurs. It can therefore make an important contribution to jobs and growth in the European Union, if encouraged and developed in a responsible manner. Driven by innovation, new business models have a significant potential to contribute to competitiveness and growth. The success of collaborative platforms are at times challenging for existing market operators and practices, but by enabling individual citizens to offer services, they also promote new employment opportunities, flexible working arrangements and new sources of income. For consumers, the collaborative economy can provide benefits through new services, an extended supply, and lower prices. It can also encourage more asset-sharing and more efficient use of resources, which can contribute to the EU's sustainability agenda and to the transition to the circular economy.

Analyzing the activities of the most important representatives of SE, which undoubtedly include Uber or Airbnb, it is easy to show the advantages of the SE-based business model compared to traditional solutions. In the case of Uber, these advantages include:

- easiness of ordering a taxi, valuation of travel and payment (by the application),

- possibility to control the length of the route by the passenger in the application,

- quality control of services based on the assessment system of drivers by passengers, 
- the mechanism of dynamic valuation of a ride based on demand reduces demand and supply fluctuations, maintaining a constant availability of services for customers.

Among the advantages, there is also an innovative business model that increases the productivity of drivers. Research from five large US cities (Cramer, Krueger, 2016) shows that compared to traditional taxi services, Uber drivers are actually $30 \%$ more productive in terms of working time in which they actually carry passengers, and in addition $50 \%$ more productive in terms of distance covered with passengers.

The positive effects of the activity are also emphasized in relation to the company Airbnb, which intermediates in renting real estate in over 35,000 cities in 192 countries around the world. The platform creates opportunities for owners to better use their (otherwise unused) resources and thereby gain additional income. From information published by Airbnb, $43 \%$ of rental income obtained through Airbnb is used to cover the cost of daily life, and $6 \%$ of hosts use income from Airbnb to start a new business. In addition, the platform brings great benefits to consumers. Thanks to Airbnb, the availability of premises increased and prices fell. According to the Airbnb Community Impact report (Airbnb, 2015), up to 35\% of Airbnb guests admit that if it had not been for the accommodation option offered by the platform, their trip would have not been as long or would not have taken place at all. As the research carried out in the area of Texas in the USA showed, the development of Airbnb affecting the competitiveness of the market, also brings other positive side effects - an increase in tourism and, as a consequence, a creation of new jobs (Zervas, Proserpio, Byers, 2017, pp. 687-705). However, along with the development of the SE sector, the negative consequences of the proliferation of exchange platforms and the business models they use are also increasingly pointed out.

The biggest critics of Uber are traditional taxi corporations for whom the platform is a direct competitor, but because this competitor is subject to lighter (if any) regulations (Henten, Windekilde, 2016, pp. 1-15), it is indicated as an example of unfair competition. The business model introduced by Uber turned out to be extremely innovative and attractive for clients, at the same time incompatible with a number of detailed regulations that have so far defined the rules of providing taxi services in various countries. In many places in the world, a number of requirements are imposed on the platform, which may lead to a temporary suspension of operations (e.g. 11 months in Finland) or a complete withdrawal from a given market (e.g. Greece).

Also in the case of Airbnb, the market and social impacts of its operation are met with criticism, which is accompanied by actions aimed at limiting the service. The previously mentioned research conducted in Texas showed the negative impact of Airbnb development on hotel revenues, especially lower-class hotels. There are also indications of negative externalities for people living near rented properties and which result from the associated nuisance (increased noise, traffic, lack of parking spaces) or a lack of sense of security due to the presence of strangers. The rapid increase in the popularity of exchange platforms in the real estate sector, which can be seen especially in places attractive for tourists, is indicated as the main reason for the uncontrolled rise in property prices and rental costs (Segu, 2018; Barron, Kung, Proserpio, 2017). Cities such as Amsterdam, Barcelona, Madrid, Hamburg, Helsinki, New York, San Francisco or Paris, trying to limit the negative effects of the popularity of shortterm rental on the real estate market, impose additional obligations on renters (registration requirement, additional taxes, time limits for renting and sanitary checks), and others such as Palma de Mallorca completely ban the activities (the ban on renting apartments in multi-family buildings) or Berlin (the ban on renting entire apartments). As a result of the steps undertaken, many people temporarily or permanently resign from renting a property. 
Negative phenomena accompanying the development of the SE and the growing pressure of professional groups or communities affected by their effects have caused an increase in interest in the issue of whether and how the operation of cooperation platforms can be regulated.

\section{Reasons and rules for sharing economy}

The problem concerning the scope and methods of state or local authorities' interference in the market economy is not new and for years, economists, politicians and entrepreneurs have been involved in a dispute over this matter. Discussions mainly concern whether the state and its institutions, having at their disposal different possibilities of influencing the functioning of business entities, should make use of these possibilities, what should be the scope, form and content of this activity. In the case of SE, it is pointed out that the introduction of regulations, in particular, excessive regulations may seriously limit the development of innovative undertakings which will affect the competitiveness of the market, the efficiency of the use of resources and the benefits that consumers derive from it. On the other hand, the lack of regulation as experience shows favours the development of negative economic and social phenomena. The conducted research and observation show that taking actions that significantly limit the interaction of cooperation platforms on the market is undesirable and against the interests of consumers. One of the conclusions in the OECD Competition Committee Report on Competition in Taxi Services of 2007 reads as follows: restrictions (limits on the number of licenses, and the provisions on the quality of cars and driver training) in terms of market entry are the biggest barrier to competitiveness in the taxi industry.

Because the discussion seems to be dominated by the voice of economists and decision-makers, who notice the negative effects of actions aimed at introducing very restrictive regulations in relation to representatives of SE as well as the ineffectiveness of such actions, the regulations introduced in this area tend to organize the market rather than to significantly reduce it (Codagnone, Martens, 2016). The most liberal proposals indicate that self-regulation based on the bottom-up model is necessary, where:

- various forms of licensing should be reduced to allow private certification schemes and reputation mechanisms to evolve,

- regulations making it difficult for start-ups to compete for labour (contractors should not be turned into employees) should be avoided,

- regulation should remain general and not industry specific.

On the other hand, there are less radical proposals that emphasize the diversity and specificity of the SE phenomenon. The regulations that are consistent with this approach should be innovative and intelligent, and their main goal should be to achieve a compromise between SE sector entities and the environment, while at the same time ensuring consumer protection and safety without limiting the development of new and innovative services.

A step towards introducing clear rules regarding the functioning of the SE in the EU countries was the publication by the EC in June 2016 of guidelines for market authorities and regulators regarding the functioning and promotion of the sustainable development of new business models based on the SE concept. The guidelines indicate that:

1. The entity providing the so-called sharing economy services may be required to obtain a license or a business license only if it is necessary from a public interest perspective.

2. Internet platforms, which are only intermediaries associating people offering services (e.g. accommodation or transport) and consumers, should not be obliged to obtain a license. It is necessary to distinguish (e.g. 
by introducing thresholds) between services provided occasionally by individuals and professional service providers.

3. Both internet platforms and people providing sharing economy services should pay taxes equally with other market participants, including income taxes, business and VAT taxes. At the same time, EU countries should simplify tax regulations for this sector.

4. Online platforms do not have to be responsible for the information they collect on behalf of service providers, but they should not be exempt from liability for any service they provide themselves, such as for the payment of a service.

5. National regulations should also guarantee a high level of consumer protection against unfair practices, with the proviso that occasional service providers of sharing economy will not bear disproportionately large burdens (European Commission, 2016).

The EC also recommends specifying in which circumstances a person offering a service via an online platform can be considered to be employed by this platform (e.g. by determining the nature of the work performed or the method of remuneration).

In June 2017, the European Parliament issued resolutions aimed at clarifying the above principles (especially in the field of employment and social security) and creating a coherent framework for the operation of SE enterprises within the European Single Market. The resolution expresses particular concerns regarding the accommodation, transport and energy sectors and points out what could be a work plan for future regulation of the sharing economy:

1. Market Access: market access requirements for collaborative platforms and service providers must be necessary, justified and proportionate, as well as simple and clear. Effective criteria to distinguish between "peers" (e.g. individual citizens providing services on an occasional basis) and "professionals" are needed, with general principles at EU level and thresholds at national level (e.g. based on income).

2. Consumer Protection: occasional service providers should comply with consumer protection rules, on the same or on a comparable basis as professional service providers. Consumers should be informed about the rules applicable to each transaction and their rights. Collaborative platforms should put in place effective systems for complaints and for settling disputes. For many occasional sharing economy service providers this suggestion could significantly impact the way they offer their services. Sharing economy platforms would need to consider how to assist their users which only occasionally offer services in complying with such potential requirements.

3. Direct and Intermediary Liability: the EU Commission should further clarify the collaborative platforms' liability as quickly as possible. The Parliament particularly identified the lack of legal certainty regarding the question of whether a platform provides only an online service or in fact the underlying service (e.g. transport services).

4. Labor Law and Workers' Rights: the resolution underlines the paramount importance of safeguarding workers' rights in the collaborative services, including the right of workers to organise in unions, the right of collective bargaining and action, fair working conditions and adequate legal and social protection. One tangible action item the Parliament demands is that workers should also be able to transfer and accumulate users' electronic ratings and reviews from one platform to another as these ratings "constitute their digital market value". 
5. Tax: the Parliament suggests that similar tax obligations should be applied to businesses providing comparable services, whether in the traditional economy or in the collaborative economy. Hence, the resolution advocates for innovative solutions to improve tax compliance and calls on platforms to collaborate to this end (European Parliament, 2017).

At the moment it is difficult to assess the effectiveness of the above recommendations mainly due to the short period of their validity. There is also a lack of extensive research (especially in the EU) referring to the effects of regulatory actions taken in relation to entities operating in the SE area.

An additional difficulty may be the fact that the regulated platforms may significantly change the scope of activities and business models, and with the development of technologies and the possibilities they will create, they may pose new regulatory challenges.

\section{Conclusions}

The emergence and development of the phenomenon known as sharing economy cause changes in the economic and social sphere that were considered crucial, because they concern various fields, sectors of the economy, business models and lifestyles or management styles.

Innovative solutions in terms of products and services offered and business models used have a particular impact on business operations and limit barriers to access to markets and resources. They also significantly change preferences and behaviours regarding ownership and consumption, and thanks to the widespread use of reputation assessment mechanisms they lead to eliminating the problem of trust and, as a result, to profound social changes. The rapid increase in the popularity of services offered through exchange platforms proves that they are positively received and accepted by users. Studies and reports emphasize that sharing economy/collaborative economy services can have a positive impact on economic growth and job creation. However, the increasingly negative effects appearing along with the uncontrolled development of this sector are becoming a challenge. Central to the debate on the subject of SE are issues regarding the scope and manner of regulation of this area. The actions undertaken by individual states, local units or international organizations are currently aimed at creating a regulatory framework and effective rules for eliminating unfavourable phenomena that SE can create. However, taking into account the special nature of the SE phenomenon itself which is based on modern information technologies and therefore subject to very rapid and significant changes, the implementation of effective regulations is not an easy process. This means both the necessity and the opportunity to undertake research, the effect of which will be to assess the current actions and maximize the positive effects that result from the development of the SE.

\section{References}

Airbnb (2015). The Airbnb Community Compact. Retrieved from: https://2sqy5r1jf93u30kwzc1smfqt-wpengine.netdna-ssl.com/wpcontent/uploads/2015/11/Airbnb-Community-Compact.pdf.

Barron, K., Kung, E., Proserpio, D. (2017). The Sharing Economy and Housing Affordability: Evidence from Airbnb. Retrieved from: https://papers.ssrn.com/sol3/papers.cfm?abstract_id=3006832.

Budziewicz-Guźlecka, A. (2017). Role of the sharing economy in the contemporary economy. Ekonomiczne Problemy Usług, 1 (126), 27-36.

Codagnone, C., Martens, B. (2016). Scoping the Sharing Economy: Origins, Definitions, Impact and Regulatory Issues. European Union: Institute for Prospective Technological Studies Digital Economy, Working Paper 01, JRC100369. Retrieved from: https:// ec.europa.eu/jrc/sites/jrcsh/files/JRC100369.pdf. 
Cramer, J., Krueger, A.B. (2016). Disruptive Change in the Taxi Business: The Case of Uber. American Economic Review, 106 (5), 177-182.

Cusumano, M.A. (2018). The Sharing Economy Meets Reality. Communications of the ACM, 61 (1), $26-28$.

DC (2016). Report On Digital Matching Firms. Retrieved from: https://www.commerce.gov/news/press-releases/2016/06/ us-department-commerce-releases-new-report-digital-matching-firms.

European Commission (2016). Communication from The Commission to The European Parliament. A European agenda for the collaborative economy COM/2016/0356 final.

European Commission (2018). The use of the collaborative economy, Survey requested by the European Commission, DirectorateGeneral for Internal Market, Industry, Entrepreneurship and SMEs, Flash Eurobarometer 467.

European Parliament (2017). European Parliament resolution of 15 June 2017 on a European Agenda for the collaborative economy. Retrieved from: www.europarl.europa.eu/sides/getDoc.do?type=TA\&language=EN\&reference=P8-TA-2017-0271.

Henten, A.H., Windekilde, I.M. (2016). Transaction Costs and the Sharing Economy. Info 18 (1), 1-15.

Laurell, C., Sandström, C. (2017). The sharing economy in social media: Analyzing tensions between market and non-market logics. Technological Forecasting and Social Change, 125, 58-65.

Mair, J., Reischauer, G. (2017). Capturing the dynamics of the sharing economy: Institutional research on the plural forms and practices of sharing economy organizations. Technological Forecasting and Social Change, 125, 11-20.

Muñoz, P., Cohen, B. (2017). Mapping out the sharing economy: A configurational approach to sharing business modeling. Technological Forecasting and Social Change, 125, 21-37.

Owyang, J. (2016). Honeycomb 3.0: The Collaborative Economy Market Expansion. Retrieved from: www.web-strategist.com/ blog/2016/03/10/honeycomb-3-0-the-collaborative-economy-market-expansion-sxsw.

Segu, M. (2018). Do short-term rent platforms affect rents? Evidence from Airbnb in Barcelona. MPRA Paper No. 84369. Retrieved from: https://mpra.ub.uni-muenchen.de/84369.

Zervas, G., Proserpio, D., Byers, J.W. (2017). The rise of the sharing economy: Estimating the impact of Airbnb on the hotel industry. International Journal of Research in Marketing, 54 (5), 687-705.

Cite this article aS: Ładny, P. (2018). Sharing economy - challenges and regulatory requirements. European Journal of Service Management, 4 (28/1), 173-180. DOI: 10.18276/ejsm.2018.28/1-22. 